\title{
Short communication: Detection of lameness in dairy cows using a grooming device
}

\author{
R. Mandel, ${ }^{*} \dagger^{1}$ H. Harazy, ${ }^{*}$ L. Gygax, $\ddagger^{2}$ C. J. Nicol,§ A. Ben-David,\# H. R. Whay,§ and E. Klement* \\ ${ }^{*}$ Koret School of Veterinary Medicine, Robert H. Smith Faculty of Agriculture, Food and Environment, The Hebrew University, Rehovot 76100 , \\ Israel \\ †Department of Environmental Systems Science, Institute of Agricultural Sciences, ETH Zürich, Zurich 8092, Switzerland \\ ¥Centre for Proper Housing of Ruminants and Pigs, Federal Food Safety and Veterinary Office, Agroscope Tänikon, Switzerland \\ $\S S c h o o l$ of Veterinary Science, University of Bristol, BS40 5DU, United Kingdom \\ \#Hachaklait Veterinary Services Ltd., PO Box 3039 Caesarea, Israel
}

\section{ABSTRACT}

Lameness in dairy cattle is a common welfare problem with significant economic implications. All too often, appropriate treatment is delayed or neglected due to insufficient detection of lame cows. Brush usage is considered a low-resilience activity; that is, one that typically decreases when energy resources are limited or when the cost involved in the activity increases, such as during sickness and stress. The aim of this study was to determine the association between brush usage and different degrees of lameness. Locomotion scores of 209 lactating Holstein dairy cows were collected individually once a week for 14 consecutive weeks, using a 5 -point visual assessment scoring system $(1=$ nonlame, $2=$ uneven gait, $3=$ mild lameness, $4=$ lameness, $5=$ severe lameness). Daily brush usage was collected automatically from 3 cowsheds of similar size and structure located on a commercial dairy farm. In each of the 3 cowsheds, 2 brushes were installed, one next to the feed bunk, and the other away from the feed bunk (on the opposite side of the cowshed). Linear and generalized linear mixed-effects models were used to evaluate the association between locomotion scores and daily measures of brush usage. We found a significant interaction between locomotion score and brush location (near to/ distant from feed bunk) on the daily proportion of cows using the brush at least once and on daily duration of brush usage. Specifically, we showed that lame and severely lame cows did not use brushes that were installed away from the feed bunk but continued to use brushes that were installed next to the feed bunk. Brush usage by cows with uneven gait (locomotion score 2) or with

\footnotetext{
Received May 22, 2017.

Accepted September 28, 2017.

${ }^{1}$ Corresponding author: roi.mandel@mail.huji.ac.il

${ }^{2}$ Current address: Albrecht Daniel Thaer-Institute of Agricultural and Horticultural Sciences, Universität zu Berlin, Philippstr. 13, House 10, 10115 Berlin, Germany.
}

mild lameness (locomotion score 3) did not differ from that of nonlame cows (locomotion score 1). The results of this study suggest that monitoring of daily usage of brushes located away from the feed bunk could be a useful method for detecting lameness and severe lameness in dairy cows. However, the use of this method to detect mild lameness or cases of abnormal gait is, at this stage, less promising.

Key words: sickness behavior, automated brush, locomotion scores

\section{Short Communication}

Lameness is a major welfare problem on the modern dairy farm (von Keyserlingk et al., 2009). Between 20 and $25 \%$ of intensively managed dairy cows worldwide are estimated to be lame at any time (Whay et al., 2003; Espejo et al., 2006; Cook and Nordlund, 2009). In dairy cows, lameness is associated with physical injury and with more than 40 different clinical conditions, including digital dermatitis, sole ulcer, and white line disease (Murray et al., 1996; Amory et al., 2008). In addition to compromising the welfare of the affected animals (Whay et al., 2003, Whay and Shearer, 2017), lameness can result in reduced milk yield (Archer et al., 2010), reduced fertility, and increased risk of premature culling (Garbarino et al., 2004; Bicalho et al., 2007), creating a substantial economic loss (Cha et al., 2010).

One of the greatest challenges in treating lameness is to overcome the difficulty of detecting the condition in its early stages (Whay et al., 2003; Espejo et al., 2006). Prey animals tend to hide signs of pain or weakness that could make them appear vulnerable to a predator, for as long as they can bear (Short, 1998; Stasiak et al., 2003). Although this strategy might be useful in an environment associated with a high risk of predation, in commercial dairy farms it simply results in the late detection of pain and its causal factors. Delayed detection of pain, and the consequent delayed medical treatment, 
causes unnecessary additional suffering to the animal (O'Callaghan et al., 2003), as well as increasing the cost of treatment (because the source of the lameness is detected only at an advanced stage).

In an effort to improve detection of lameness and to reduce the labor involved in manual assessment of cow locomotion, several indicators for lameness in cows have been suggested. Some indicators focus on monitoring physical characteristics of lame cows (e.g., distribution of weight between legs when walking or standing; Pastell and Kujala, 2007), whereas others are aimed at detecting changes in measures of production (e.g., decreased milk yield or rumination, Bach et al., 2007; de Mol et al., 2013) or changes in general behavior (e.g., activity, O'Callaghan et al., 2003; visits to the automatic milking system, Borderas et al., 2008). Monitoring changes in production (or related behaviors, such as the frequency of visits to the automatic milking system) with the aim of detecting lameness may prove to be a practical and simple method on farms that collect these measures routinely. However, the association between locomotion scores and the aforementioned behaviors is inconclusive, with some studies finding a negative association between lameness and milk yield (Warnick et al., 2001; Kocak and Ekiz, 2006; Van Hertem et al., 2013; Wadsworth et al., 2016) and between lameness and rumination (Van Hertem et al., 2013), whereas others show no strong association between lameness and these 2 measures (milk: Archer et al., 2011; Thorup et al., 2016; rumination: Thorup et al., 2016).

A possible explanation for the inconsistent results of the aforementioned studies resides in the nature of the behaviors that were used to detect lameness, which can be classified as core behaviors. Core behaviors (e.g., food consumption or related behaviors such as rumination) are essential for the short-term survival of the animal and are therefore resilient by nature (McFarland, 1999; Weary et al., 2009). When the price of a valuable resource or core behavior (e.g., food consumption) increases, animals are willing to invest the extra cost needed to engage in the activity (Dawkins, 1990). The cost, for example, can be expressed in terms of energetic demand, time, or willingness to tolerate an aversive experience (e.g., pain, Niel and Weary, 2007). Alternatively, animals can cope with the cost by modifying their behavioral strategy (Sherwin, 1998). For example, Thorup et al. (2016) found that lame cows reduce daily feeding time and feeding frequency, but their daily consumption of DM is not affected. This is because lame cows appear to compensate for the smaller time spent eating by increasing the rate of eating. The resilience of core behaviors may reveal the motivation of animals to engage in these type of behaviors, but also illustrate the challenges (e.g., predicting the type of coping strategy and interpreting the results accordingly) related to monitoring these types of behaviors to detect morbidity at an early stage (Littin et al., 2008; Weary et al., 2009).

Low-resilience behaviors (also referred to as "luxury activities") are behaviors that, unlike core behaviors, typically decrease when energy resources are limited or when the cost involved in the activity increases (McFarland, 1999; see also Dawkins, 1990). In cattle, reduced levels of low-resilience behaviors (e.g., use of automated brushes) were documented during heat load (Mandel et al., 2013), following intrusive medical procedures (Mandel et al., 2013), during metritis (Mandel et al., 2017), and on the peak day of bovine respiratory disease (Toaff-Rosenstein et al., 2014). These low-resilience behaviors might thus be more promising to detect morbidity in its early stage compared with core behaviors. The aim of the current study was to assess the role of low-resilience behaviors in the early detection of lameness. Here, we explored the association between locomotion scores and brush usage. We hypothesized that the daily proportion of cows using a brush, and the daily duration of brush usage would be inversely related to the severity of lameness. Daily measures of brush usage were also expected to decrease in case of mild lameness, in contrast to measures of core behaviors that, due to their high resilience, were expected to decrease only in more severe cases of lameness (rumination, milk yield, and general activity). To test this hypothesis, we also analyzed the effect of lameness on daily milk yield, rumination, and general activity. Furthermore, we expected that changes in our measures of brush usage would be more pronounced in brushes located away from the feed bunk, compared with brushes located next to the feed bunk, because the cost involved in utilizing the former is higher.

The study was carried out at a commercial dairy farm in the northern Negev of Israel, from September to December 2015. Routine care of the animals was provided by the farm's staff and the veterinary surgeon assigned by Hachaklait Veterinary Services Ltd. (Caesarea, Israel). The veterinary surgeon visited the farm regularly twice a week and added visits on request, and medication was given when appropriate. Daily brush usage was collected from 209 Holstein dairy cows. Cows were kept in 3 groups according to their lactation status (first lactation, second lactation, and third lactation or higher). All groups were kept year round in loose-housing cowsheds bedded with dried manure (zero-grazing system). Each group comprised 70 to 80 cows housed in a 90.0- $\times 6.6-\mathrm{m}$ cowshed. Cows were fed a TMR twice a day at 0800 and $1600 \mathrm{~h}$. In each cowshed, water was available ad libitum from 6 water troughs $(18 \mathrm{~cm}$ of trough per cow on average). Cows were milked 3 times 
a day, at 0400-0600 h, 1100-1300 h, and 1900-2100 h; the average milk yield was $36.8 \pm 8.7 \mathrm{~L} / \mathrm{d}$. During the first month of observations (September), due to warm climate conditions, all lactating cows were cooled using water showers installed at the entrance to the milking parlor. Measures of daily rumination and activity were collected electronically using HR-Tags (SCR Engineers Ltd., Netanya, Israel).

Visual assessment of locomotion was carried out once a week for 14 consecutive weeks using a 5-point scoring system $(1=$ nonlame to $5=$ severe lameness; Thomsen et al., 2008; Table 1). Locomotion was scored following the noon milking $(1200 \mathrm{~h})$ at the exit from the milking parlor, while the cows were walking down a 20-m-long concrete pathway covered with dried manure. Locomotion was assessed by a well-trained experimenter standing $11 \mathrm{~m}$ from the pathway to allow a proper view of walking gait and to allow recognition of individual cows through a unique 3- or 4-digit number that had been applied as a brand at a younger age. Locomotion scores were directly entered on a tablet computer (Nexus 9, HTC, New Taipei City, Taiwan) equipped with an Android-based scoring software developed for the purpose of this study. To verify the correct recognition of cows (i.e., in cases where the number branded on the cow was not completely clear during the locomotion assessment), scoring sessions were additionally recorded using a video camera installed $7 \mathrm{~m}$ from the pathway (HC-V160 Full HD Camcorder, Panasonic, Osaka, Japan). Using this method, the observer was able to trace back and validate, a posteriori, cow identification in 26 ratings (from a total of 1,436 ratings). To minimize the effect of novelty and the presence of the experimenter on the expression of pain behavior, the cows were habituated to the presence of the experimenter (standing at the observation point) in the week before the beginning of the observations on 5 consecutive days for $2 \mathrm{~h} / \mathrm{d}$. Consistency of ratings (i.e., intra-observer reliability) was estimated before the beginning of the study using an intra-class correlation (ICC) test based on 4 independent ratings of video recordings of 123 cows walking down the aforementioned path $\left(\operatorname{ICC}_{(2,1)}\right.$ $=0.823,95 \%$ CI: $0.775-0.864)$. When a cow was detected to be lame by the farmers, she was treated by the farm's trained hoof trimmer and received veterinary medical care if needed. In total, 1,436 ratings were collected throughout the observation period. Locomotion scores were distributed as follows: 672 ratings of score 1 ("normal"/nonlame, 154 cows), 620 ratings of score 2 (uneven gait, 159 cows), 128 ratings of score 3 (mild lameness, 60 cows), 14 ratings of score 4 (lameness, 10 cows), and 2 ratings of score 5 (severe lameness, 2 cows). Because the locomotion of each cow was scored 14 times during the experiment (once a week), the locomotion score of an individual cow could vary between weeks (lameness could improve or worsen). Throughout the observation period, 66 cows received the same score (which could vary from 1 to 4 ), 115 cows received 2 different scores, 25 cows received 3 different scores, and 3 cows received 4 different scores.

Ten months before the experiment, 6 rotating brushes (swinging cow brush SCB, DeLaval International AB, Tumba, Sweden) were installed in the dairy farm. Two brushes were installed in each cowshed. One brush was installed close to the feed bunk $(3 \mathrm{~m}$ from the feed bunk, "brush near feed bunk") and the other on the opposite side of the yard (16 m from the feed bunk, "brush distant from feed bunk"). Installing one brush next to

Table 1. Description of the 5-point ordinal lameness scoring system for dairy cows used in the study (adopted from Thomsen et al., 2008)

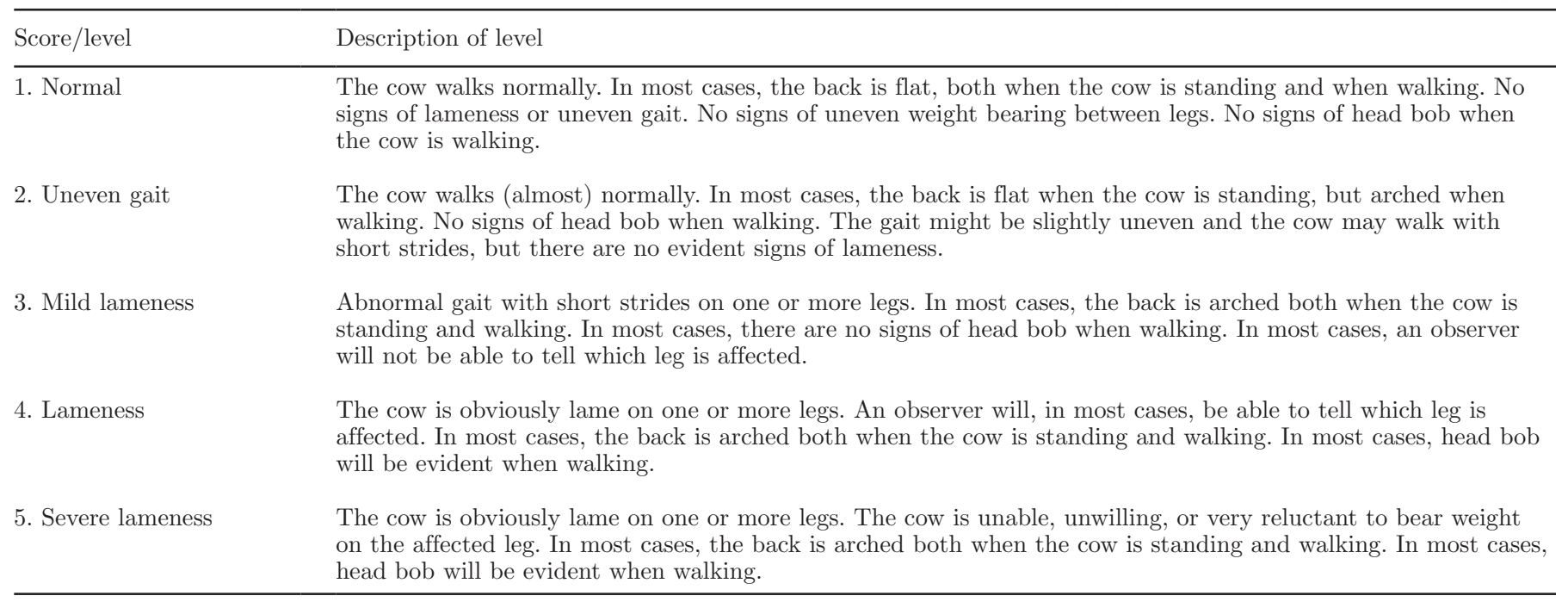


the feed bunk and the other more distant allowed us to assess the effect of the location of the brush (relative to the feed bunk) on its utilization, and to improve our ability to detect stress and morbidity by altering the cost (i.e., walking distance) involved in using the device, as shown in previous studies (Mandel et al., 2013, 2017). When mechanical pressure was applied to the brush, it started revolving. Once activated, the brush continued to rotate for $10 \mathrm{~s}$ after the cow departed. Daily brush usage was collected automatically using a brush monitoring system validated during a previous study (see Mandel et al., 2017). Tags worn on the necks of the cows transmitted an identification signal only after being activated via infrared light. Infrared light beams were limited to $1 \mathrm{~m}$ from the brush and were activated only when motion was detected under the brush and when the brush rotating function was turned on. The system allowed us to monitor the following parameters: time of brush usage (hh:mm:ss), duration of usage (in seconds), identity of the cows standing under or close to the brush (radius of $1 \mathrm{~m}$ from the brush), and the rotation status of the brush (rotating/not rotating). To reduce false registration of brush usage (e.g., when a cow was crossing next to the brush with no clear intention to use it), the data were retained for analysis only if the following criterion was met: a cow was considered to be using the brush if present in a radius of $1 \mathrm{~m}$ from the brush (based on the range of the infrared beam) for at least $10 \mathrm{~s}$, with the rotating function of the brush being on at least once during this time period (Mandel et al., 2017).

Statistical analysis was performed in $\mathrm{R}$ (version 3.0.2, $\mathrm{R}$ Core Team, 2016). To adequately reflect dependencies in the experimental design (nesting, repeated measurements), linear and generalized linear mixed-effects models (lmer and glmer functions, package lme4; Bates et al., 2015) were used to evaluate the outcome variables daily duration of brush usage (s/d) and as daily occurrence (binary; $0=$ no use, $1=$ use at least once), respectively, for each cow (unbalanced within-subject design). We analyzed brush usage in 2 ways to identify the more indicative measure. Locomotion scores from categories 4 (lameness; 14 ratings) and 5 (severe lameness; 2 ratings) were merged into one category because of the relatively small sample size. For each model, the explanatory factors were lameness score (4-level factor), brush location (near/away from feed bunk), and DIM [fitted as 1/log (DIM) based on Mandel and Nicol, 2017], and all possible interactions between these 3 factors. Lactation was not included in the model due to its collinearity with group (pen). Random effects included cow identity nested within group. Date of observation was added as a crossed-random effect because the locomotion scoring of most, but not all cows, overlapped with others, and to control for differences in temperature and humidity between days. The associations between locomotion scores and milk yield, rumination, and activity collected on the day of locomotion assessment were assessed using 3 different models (one for each dependent variable), with locomotion score and DIM (fitted as a quadratic term) as explanatory factors. The random structure for these models was cow identity nested within group. Date of observation was added as a crossed-random effect. For each model, nonsignificant interaction terms were removed using a stepwise backward elimination. The significance of each term (explanatory factors or interactions) was assessed by comparing the model with and without the factor included using likelihood ratio tests (LRT). The level indicating statistical significance was set at $\alpha=$ 0.05. The residuals were checked graphically for normal distribution and homoscedasticity. To satisfy assumptions, we used a log-transformation for daily duration of brush usage. Post hoc pair-wise comparisons between nonlame cows and cows with higher locomotion scores were conducted using a Bonferroni correction. The results are presented as model estimates and $95 \%$ CI.

We found an interaction between locomotion score and brush location (near/away from feed bunk) on the proportion of cows using the brush $\left[\chi^{2}\right.$ with $3 \mathrm{df}\left(\chi_{3}^{2}\right)=$ $9.41, P=0.025]$ and daily duration of brush usage $\left(\chi^{2}{ }_{3}\right.$ $=11.19, P=0.011)$. We therefore split the data by brush location for the above measures. For brushes installed away from the feed bunk, locomotion scores were associated with the daily proportion of cows using the brush at least once $\left(\chi_{3}^{2}=24.15, P<0.0001\right)$ and daily duration of brush usage $\left(\chi_{3}^{2}=9.92, P=0.019\right)$. Specifically, both measures of brush usage dropped at the most severe lameness score (see Table 2 for model estimates). For brushes installed next to the feed bunk, we did not find statistical support for an association between brush usage and the proportion of cows using the brush $\left(\chi_{3}^{2}=3.81, P=0.28\right)$ or daily duration of brush usage $\left(\chi_{3}^{2}=6.70, P=0.08\right)$. Locomotion scores were also significantly associated with daily milk yield $\left(\chi^{2}{ }_{3}\right.$ $=14.30, P=0.026)$, daily rumination $\left(\chi^{2}{ }_{3}=7.96, P=\right.$ $0.047)$, and daily activity $\left(\chi_{3}^{2}=10.48, P=0.015\right.$; see Table 2 for model estimates and pair-wise comparisons between lameness scores).

Our results show that lame and severely lame cows did not use brushes that were located away from the feed bunk but continued to use brushes that were installed next to the feed bunk (Figure 1). In contrast to our prediction, however, brush usage of mildly lame cows and cows with uneven gait (locomotion scores 3 and 2, respectively) did not differ markedly from that of nonlame cows, either in daily duration of brush usage or the daily proportion of cows using the brush 
(a)

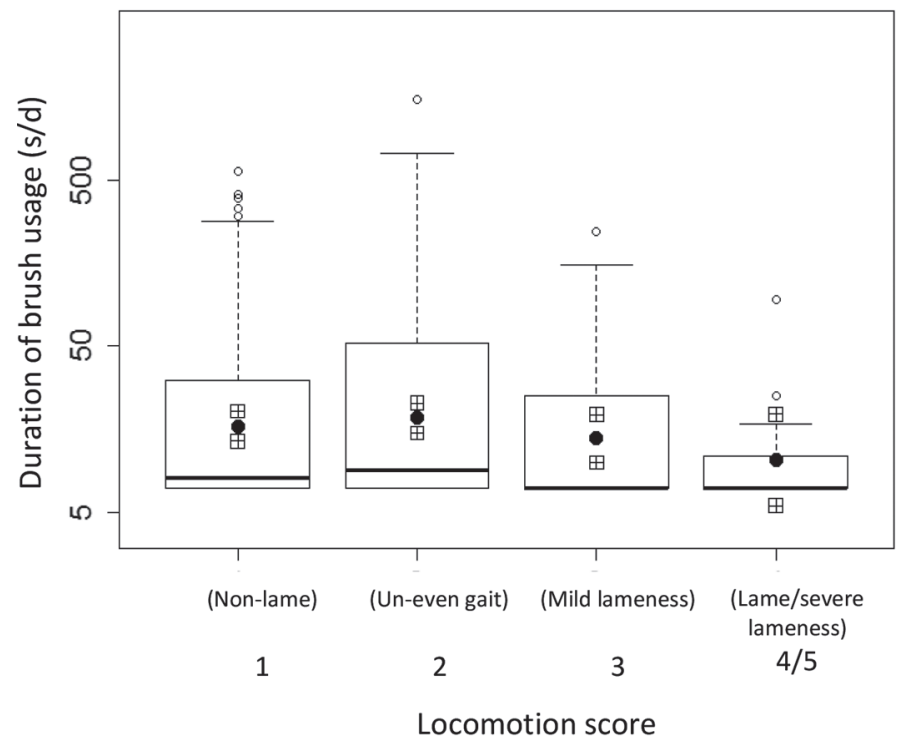

(b)

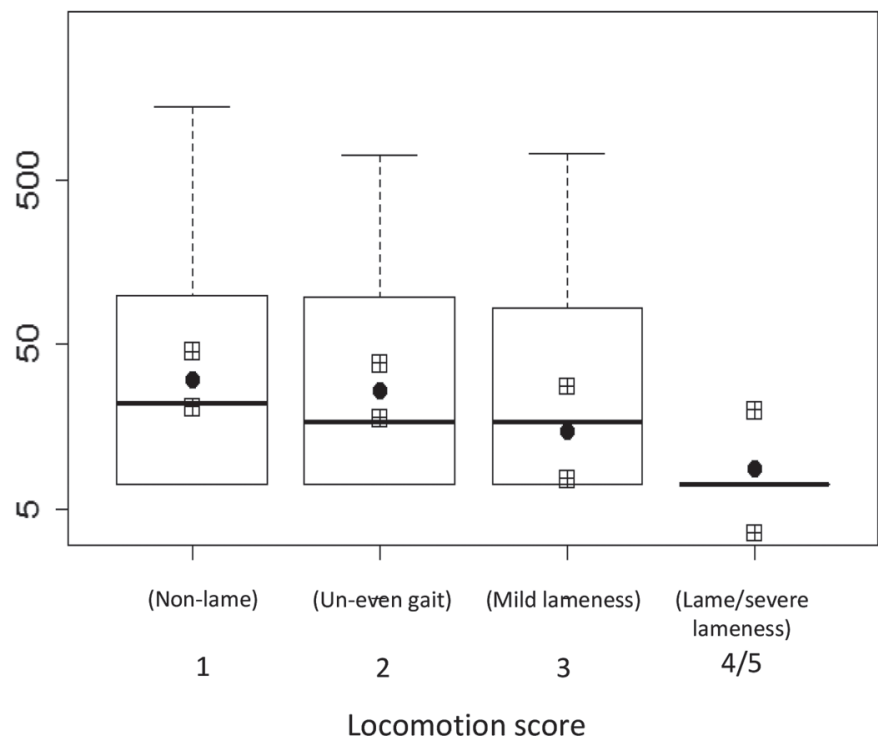

Figure 1. Daily duration of usage (in seconds) as a function of locomotion score for (a) brushes installed near the feed bunk, and (b) brushes installed away from the feed bunk. Box plots reflect raw data (minimum, lower quartile, median, upper quartile, maximum); filled black circles represent model estimates and square plus represent upper and lower $95 \% \mathrm{CI}$; and open circles are outliers. Lame and severely lame cows did not use the distant brushes during the days when locomotion scores were assessed.

at least once. Among the 3 measures of core behavior that we considered (daily milk yield, rumination, and activity), only milk yield was found to be lower for lame and severely lame cows compared with nonlame cows. This measure was also lower for cows with uneven gait compared with nonlame cows, but it did not differ between mildly lame and nonlame cows (Table 2). Daily rumination and daily activity were significantly associated with locomotion scores; however, post hoc comparisons revealed that cows with uneven gait or mild lameness and lame and severely lame cows were not statistically different from nonlame cows in these 2 measures (Table 2).

Our failure to detect reduced brush usage among mildly lame cows and cows with uneven gait, compared with nonlame cows, could be attributed to several factors. First, lame and severely lame cows are expected to suffer from a higher degree of pain when shifting

Table 2. Association between locomotion scores and usage of distant brushes, milk yield, rumination, and activity (model estimates with $95 \%$ CI in parentheses)

\begin{tabular}{|c|c|c|c|c|}
\hline Item & \multicolumn{4}{|c|}{ Locomotion score ${ }^{1}$} \\
\hline Number of scores & 672 & 620 & 128 & 16 \\
\hline \multicolumn{5}{|c|}{ Brush distant from feed bunk } \\
\hline Proportion (cows/d) & $0.24(0.1-0.4)$ & $0.21(0.1-0.4)$ & $0.17(0.0-0.4)$ & $0.0(0.0-0.0) * * *$ \\
\hline Proportion (cows/d) & $0.24(0.1-0.5)$ & $0.23(0.1-0.5)$ & $0.20(0.0-0.5)$ & $0.08(0.0-0.4)$ \\
\hline Duration $(\mathrm{s} / \mathrm{d})$ & $16.4(13.4-20.3)$ & $18.6(15.0-22.8)$ & $14.0(9.9-19.4)$ & $10.4(5.5-19.4)$ \\
\hline Milk (L/d) & $37.1(32.9-40.7)$ & $36.0(31.9-39.8)^{*}$ & $35.5(31.3-39.3)$ & $32.9(27.9-37.9) *$ \\
\hline Rumination $(\mathrm{min} / \mathrm{d})$ & $521.3(497.8-546.4)$ & $511.6(487.2-535.3)$ & $500.7(472.3-527.8)$ & $494.5(453.9-535.7)$ \\
\hline Activity (per day) & $664.7(621.9-708.7)$ & $678.9(635.2-722.1)$ & $645.3(595.1-695.0)$ & $630.2(561.6-701.0)$ \\
\hline
\end{tabular}

${ }^{1}$ Locomotion was assessed up to 14 times per cow (repeated-measures design).

${ }^{2}$ Post hoc comparisons were not carried out because none of the measures of brush usage (daily duration and daily proportion of cows using the brush) were significantly associated with locomotion scores in brushes located near the feed bunk.

Statistical significance of pair-wise comparisons with nonlame cows (locomotion score 1) after applying Bonferroni correction for post hoc multiple comparisons, ${ }^{*} P<0.05, * * * P<0.001$. 
weight to the injured leg. It could be argued, therefore, that the motivation of mildly lame cows or cows with uneven gait to engage in brush usage simply exceeded the cost of experiencing pain when walking a greater distance. This effect might be even stronger in the case of hyperalgesia, which has been shown to occur in lame and severely lame cows and may last up to $4 \mathrm{wk}$ following detection and treatment of the factor causing lameness (Whay et al., 1998; Shearer et al., 2013; for a review, see Viñuela-Fernández et al., 2007). A second explanation is based on the likelihood of severe cases of lameness, compared with milder cases of lameness, to be associated with an inflammatory response leading to fever. According to Hart (1988), the reduced activity expressed during the state of a disease ("sickness behavior"; e.g., lethargy, sleepiness, and depression) is part of a strategy to save energy (and minimize heat loss), allowing animals to cope with the energetic costs of fever (estimated to increase metabolism by up to 50\%; Hart, 1988). It could be argued that because uneven gait and mild lameness are less likely to be associated with inflammation or to be associated with milder inflammation compared with severe cases of lameness, brush usage of the former did not differ from that of nonlame cows. This explanation, however, does not correspond with the findings of Mandel et al. (2017), who documented reduced brush usage during metritis in the absence of fever. A possible explanation for these discrepancies is that the study of Mandel et al. (2017) was carried out in a period when cows are expected to be in a negative energy balance (i.e., in the weeks following partum), making the cost of morbidity, even in the absence of fever, high enough to result in the animal allocating energy to other activities. Improving the sensitivity of brush usage as an indicator of mild lameness could be achieved by increasing the cost an animal needs to invest to use the brush (e.g., walking a greater distance). However, this would also make the brush less accessible for lactating cows to express their need for contact following calving (Mandel and Nicol, 2017) and as an enrichment tool (Mandel et al., 2016).

In our previous study, we suggested that the lowresilience characteristics of brush usage, in addition to being used as an early indicator of morbidity, could be used to assess recovery from disease (Mandel et al., 2017). The insensitivity of brush usage to detect mild lameness and cases of uneven gait, however, suggests that the future use of this tool to monitor recovery from hyperalgesia associated with lameness is less promising. To conclude, the current results suggest that monitoring dairy cows' usage of brushes installed away from the feed bunk could be a useful tool for detecting lameness and severe lameness. However, this measure might not be suitable for detecting mild lameness or uneven gait.

\section{ACKNOWLEDGMENTS}

We are grateful to the Harry and Sylvia Hoffman Leadership and Responsibility Program (Hebrew University, Jerusalem, Israel) and the Universities Federation for Animal Welfare, Support of Animal Welfare in Israel (UFAW-SAWI) fund (Wheathampstead, UK) for funding R. Mandel and this research, and to Elodie F. Briefer (Ethology and Animal Welfare Unit, Department of Environmental Systems Science, Institute of Agricultural Sciences, ETH Zürich) for commenting on the manuscript.

\section{REFERENCES}

Amory, J. R., Z. E. Barker, J. L. Wright, S. A. Mason, R. W. Blowey, and L. E. Green. 2008. Associations between sole ulcer, white line disease and digital dermatitis and the milk yield of 1824 dairy cows on 30 dairy cow farms in England and Wales from February 2003-November 2004. Prev. Vet. Med. 83:381-391.

Archer, S. C., M. J. Green, and J. N. Huxley. 2010. Association between milk yield and serial locomotion score assessments in UK dairy cows. J. Dairy Sci. 93:4045-4053.

Archer, S. C., M. J. Green, A. Madouasse, and J. N. Huxley. 2011. Association between somatic cell count and serial locomotion score assessments in UK dairy cows. J. Dairy Sci. 94:4383-4388.

Bach, A., M. Dinarés, M. Devant, and X. Carré. 2007. Associations between lameness and production, feeding and milking attendance of Holstein cows milked with an automatic milking system. J. Dairy Res. 74:40-46.

Bates, D., M. Maechler, B. Bolker, and S. Walker. 2015. Fitting linear mixed-effects models using lme4. J. Stat. Softw. 67:1-48.

Bicalho, R. C., F. Vokey, H. N. Erb, and C. L. Guard. 2007. Visual locomotion scoring in the first seventy days in milk: Impact on pregnancy and survival. J. Dairy Sci. 90:4586-4591.

Borderas, T. F., A. Fournier, J. Rushen, and A. M. B. De Passille. 2008. Effect of lameness on dairy cows' visits to automatic milking systems. Can. J. Anim. Sci. 88:1-8.

Cha, E., J. A. Hertl, D. Bar, and Y. T. Gröhn. 2010. The cost of different types of lameness in dairy cows calculated by dynamic programming. Prev. Vet. Med. 97:1-8.

Cook, N. B., and K. V. Nordlund. 2009. The influence of the environment on dairy cow behavior, claw health and herd lameness dynamics. Vet. J. 179:360-369.

Dawkins, M. S. 1990. From an animal's point of view: Motivation, fitness, and animal welfare. Behav. Brain Sci. 13:1-9.

de Mol, R. M., G. André, E. J. B. Bleumer, J. T. N. Van der Werf, Y. De Haas, and C. G. Van Reenen. 2013. Applicability of day-to-day variation in behavior for the automated detection of lameness in dairy cows. J. Dairy Sci. 96:3703-3712.

Espejo, L. A., M. I. Endres, and J. A. Salfer. 2006. Prevalence of lameness in high-producing Holstein cows housed in freestall barns in Minnesota. J. Dairy Sci. 89:3052-3058.

Garbarino, E. J., J. A. Hernandez, J. K. Shearer, C. A. Risco, and W. W. Thatcher. 2004. Effect of lameness on ovarian activity in postpartum Holstein cows. J. Dairy Sci. 87:4123-4131.

Hart, B. L. 1988. Biological basis of the behavior of sick animals. Neurosci. Biobehav. Rev. 12:123-137.

Kocak, O., and B. Ekiz. 2006. The effect of lameness on milk yield in dairy cows. Acta Vet. Brno 75:79-84.

Littin, K., A. Acevedo, W. Browne, J. Edgar, M. Mendl, D. Owen, C. Sherwin, H. Würbel, and C. Nicol. 2008. Towards humane end points: Behavioural changes precede clinical signs of disease in a Huntington's disease model. Proc. Biol. Sci. 275:1865-1874.

Mandel, R., and C. J. Nicol. 2017. Re-direction of maternal behaviour in dairy cows. Appl. Anim. Behav. Sci. 195:24-31. https://doi.org/ 10.1016/j.applanim.2017.06.001. 
Mandel, R., C. J. Nicol, H. R. Whay, and E. Klement. 2017. Short communication: Detection and monitoring of metritis in dairy cows using an automated grooming device. J. Dairy Sci. 100:5724-5728.

Mandel, R., H. R. Whay, E. Klement, and C. J. Nicol. 2016. Invited review: Environmental enrichment of dairy cows and calves in indoor housing. J. Dairy Sci. 99:1695-1715.

Mandel, R., H. R. Whay, C. J. Nicol, and E. Klement. 2013. The effect of food location, heat load, and intrusive medical procedures on brushing activity in dairy cows. J. Dairy Sci. 96:6506-6513.

McFarland, D. 1999. Animal Behaviour. 3rd ed. Addison Wesley Longman, Reading, UK.

Murray, R. D., D. Y. Downham, M. J. Clarkson, W. B. Faull, J. W. Hughes, F. J. Manson, J. B. Merritt, W. B. Russell, J. E. Sutherst, and W. R. Ward. 1996. Epidemiology of lameness in dairy cattle: description and analysis of foot lesions. Vet. Rec. 138:586-591.

Niel, L., and D. M. Weary. 2007. Rats avoid exposure to carbon dioxide and argon. Appl. Anim. Behav. Sci. 107:100-109.

O'Callaghan, K. A., P. J. Cripps, D. Y. Downham, and R. D. Murray. 2003. Subjective and objective assessment of pain and discomfort due to lameness in dairy cattle. Anim. Welf. 12:605-610.

Pastell, M. E., and M. Kujala. 2007. A probabilistic neural network model for lameness detection. J. Dairy Sci. 90:2283-2292.

R. Core Team. 2016. R: A language and environment for statistical computing. R Foundation for Statistical Computing, Vienna, Austria. https://www.R-project.org/

Shearer, J. K., M. L. Stock, S. R. Van Amstel, and J. F. Coetzee. 2013. Assessment and management of pain associated with lameness in cattle. Vet. Clin. North Am. Food Anim. Pract. 29:135-156.

Sherwin, C. M. 1998. The use and perceived importance of three resources which provide caged laboratory mice the opportunity for extended locomotion. Appl. Anim. Behav. Sci. 55:353-367.

Short, C. E. 1998. Fundamentals of pain perception in animals. Appl. Anim. Behav. Sci. 59:125-133.

Stasiak, K. L., D. O. N. Maul, E. French, P. W. Hellyer, and S. Vandewoude. 2003. Species-specific assessment of pain in laboratory animals. Contemp. Top. Lab. Anim. Sci. 42:13-20.

Thomsen, P. T., L. Munksgaard, and F. A. Tøgersen. 2008. Evaluation of a lameness scoring system for dairy cows. J. Dairy Sci. 91:119-126.
Thorup, V. M., B. L. Nielsen, P. E. Robert, S. Giger-Reverdin, J. Konka, C. Michie, and N. C. Friggens. 2016. Lameness affects cow feeding but not rumination behavior as characterized from sensor data. Front. Vet. Sci. 3:37.

Toaff-Rosenstein, R. L., L. J. Gershwin, A. J. Zanella, C. B. Tucker, and R. Toaff-Rosenstein. 2014. Characterizing the BRD sickness response - Opportunities for improved disease detection. In 4th Int. Symp. Beef Cattle Welfare. Iowa State University, Ames.

Van Hertem, T., E. Maltz, A. Antler, C. E. B. Romanini, S. Viazzi, C. Bahr, A. Schlageter-Tello, C. Lokhorst, D. Berckmans, and I. Halachmi. 2013. Lameness detection based on multivariate continuous sensing of milk yield, rumination, and neck activity. J. Dairy Sci. 96:4286-4298.

Viñuela-Fernández, I., E. Jones, E. M. Welsh, and S. M. FleetwoodWalker. 2007. Pain mechanisms and their implication for the management of pain in farm and companion animals. Vet. J. 174:227239

von Keyserlingk, M. A. G., J. Rushen, A. M. de Passillé, and D. M. Weary. 2009. Invited review: The welfare of dairy cattle-Key concepts and the role of science. J. Dairy Sci. 92:4101-4111.

Wadsworth, B. A., A. Stone, J. Clark, and J. Bewley. 2016. Identification of lameness using lying time, rumination time, neck activity, reticulorumen temperature, and milk yield. J. Anim. Sci. 94:29.

Warnick, L. D., D. Janssen, C. L. Guard, and Y. T. Grohn. 2001. The effect of lameness on milk production in dairy cows. J. Dairy Sci. 84:1988-1997.

Weary, D. M., J. M. Huzzey, and M. A. G. von Keyserlingk. 2009. Board-invited review: Using behavior to predict and identify ill health in animals. J. Anim. Sci. 87:770-777.

Whay, H. R., D. C. J. Main, L. E. Green, and A. J. F. Webster. 2003. Observations and investigation of farm. Vet. Rec. 153:197-202.

Whay, H. R., and J. K. Shearer. 2017. The impact of lameness on welfare of the dairy cow. Vet. Clin. North Am. Food Anim. Pract. 33:153-164.

Whay, H. R., A. E. Waterman, A. J. F. Webster, and J. K. O'brien. 1998. The influence of lesion type on the duration of hyperalgesia associated with hindlimb lameness in dairy cattle. Vet. J. $156: 23-29$ 